\title{
WHAT REALLY MATTERS IN ONLINE EDUCATION?
}

\author{
Wenli Wang, Robert Morris University, wangw@rmu.edu \\ Alan Peslak, Penn State University, arp14@psu.edu \\ Paul Kovacs, Robert Morris University, kovacs@rmu.edu \\ Lisa Kovalchick, California University of Pennsylvania,kovalchick@calu.edu
}

\begin{abstract}
The delivery of courses, programs and degrees in the online format is well established in institutions of higher education. However, educational institutions and students may have different reasons for choosing online education. This research surveyed over four hundred students in three different universities and identified "Perceived Effectiveness of Online Courses" and "Classroom Interaction and Discussion" as two significant factors that affect students' selecting of online courses, as opposed to on-ground (i.e., face-to-face) or hybrid courses. With the maturity of online education, the emphasis on the mechanism (i.e., the "technology") of course delivery has lessened in comparison to the early days of online education. It is the quality of education, proxied in educational effectiveness and course structure (e.g., classroom interaction) that really matters. In addition, online education is not "one size fits all." This studyy finds that students who selected an online course for the initial reason of "scheduling" were significantly influenced by perceived effectiveness of online courses, age, and the ability to prioritize, but not classroom interaction and discussion. This differs from students who selected an online course based on convenience and selecting a particular professor or other specific factors.
\end{abstract}

Keywords: Online Education, Computer Information Systems, Perceived Learning, e-Learning, Education Effectiveness

\section{INTRODUCTION}

Throughout higher education, online learning has emerged as a fundamental influence in educational delivery systems. The Babson Survey Research Group has been tracking online education for more than a decade with data collected from more than 2,800 colleges and universities (Allen \& Seaman, 2015). This research group has found that institutions are incorporating online classes in their long-term strategies significantly more today than they did when the first survey began in 2002. The number of students enrolled in online courses has increased from about 1.6 million in 2002 to 5.8 million in 2014 (Allen \& Seaman, 2015). For the institutions, online education can be cost-effective and provide growth opportunities (Bristow, Shepherd, Humpreys, \& Ziebell, 2011). Administration in higher education view online courses as more cost-effective than face-to-face courses, because they are not required to provide physical space for the courses. Cost-savings for the institutions may not benefit the students. It is important to determine the factors that influence students' choosing online vs. face-to-face courses.

The Noel-Levitz National Online Learners Priorities Report (2012) indicates that out of eleven enrollment factors the top three priorities for both undergraduate and graduate students choosing to enroll in online programs were: convenience, flexible programming, and the ability to fit education into their work schedule. The survey results were based on data from more than 123,000 students at 109 institutions with 112,000 of these students enrolled primarily in online programs, while students enrolled primarily on campus include approximately 10,000 students. There were a little over 79,000 undergraduate students in the dataset and around 38,500 graduate level students. This report also found that twenty-four percent $(24 \%)$ of online learners believe the experience met their expectations, sixty-five percent $(65 \%)$ considered that it exceeded their expectations and seventy-three percent $(73 \%)$ were satisfied or very satisfied with their experience

In a more recent study in 2017 (The Noel-Levitz National Online Learners Priorities Report, 2017), these three priorities (convenience, work schedule, and flexible pacing for completing a program) still matter and echo with the top three factors in students' original decision to enroll in online programs in 2012. The 2017 survey results were 
based on the feedback from 128,988 students from 164 institutions with $94 \%$ primarily online and $6 \%$ primarily onground. It is worth noting that seventy-four percent (74\%) of online learners were satisfied with their online programs, and it is the highest overall satisfaction in educational experiences, in comparison to those of the other five groups of students (four-year private, four-year public, two-year public, career schools, and adult learners).

It has been slightly over a decade since the university administrators at the authors' respective universities included the online delivery format as a critical component of their long-term strategy. The primary goal was to reach a potential student population, who were unable to attend on-ground (i.e., face-to-face) classes due to location, work schedule and the like. Another goal was to offer education to students at a price that was less expensive than conventional onground education. Nevertheless, the preference of course delivery formats by the administrations may not align with the preference of the student. Although the overall satisfaction is high from online learners in the 2017 Noel-Levitz National Student Satisfaction and Priorities Report, the result was based on 94\% primarily online students, and hence, it was unclear what a student's preference would be when given a choice of enrolling in an online or an on-ground course.

Accordingly, the purpose of this research is to develop insights into why students choose the online learning format, as compared to the traditional on-ground or the hybrid learning formats. Hannay and Newvine (2006) examined why students chose distance education and student perceptions of the quality and difficulty of those courses as compared to courses taught face-to-face. They found that students preferred the distance education format because it permitted them to balance their other commitments. Vidanagama (2016) applied the Technology Acceptance Model to investigate the acceptance of the e-learning approach among undergraduate students enrolled in computer-related degrees. The author found that the technological adequacy of the student affects why the student chose the online course format.

This research further develops insights into students' preferences in online education beyond technical factors. It focuses on Computer Information Systems (CIS) courses, particularly, to examine, for relatively technical-savvy CIS students, what other non-technical factors may influence students' online education preferences. The authors administered a survey to both on-ground and online students enrolled in CIS courses. Specifically, it was to examine the factors related to education, itself, such as course outcome and structure, besides the typically reasons of convenience, work schedule, and flexible pacing to complete a program (Noel-Levitz, 2017), which are the traits technology offers.

Research Question 1. What factors, other than convenience, flexibility and work schedule may affect a student's selection of an online delivery format over on-ground or hybrid formats?

Research Question 2. Do factors related to course outcome and course structure affect a student's selection of an online delivery format over on-ground or hybrid formats? If so, what are these factors?

Research Question 3. Do age and gender play a role in a student's selection of an online course delivery format over on-ground or hybrid formats?

\section{RESEARCH METHODOLOGY}

\section{Definition of Delivery Formats}

The definition of online course delivery is a course in which one hundred percent $(100 \%)$ of the content is delivered with no face-to-face meetings. On-ground or face-to-face courses are defined as those in which one hundred percent $(100 \%)$ of the content delivery is in the traditional brick-and-mortar classroom. Although an on-ground course might contain Web enhancements or online supplements such as assignments, videos and threaded discussions, the format of the course delivery is still considered on-ground. Finally, the hybrid delivery format occurs, when a course is partially delivered on-ground and partially delivered online (i.e., between $30 \%$ and $80 \%$ of the course content is delivered online). 


\section{Survey and Participants}

The researchers used a web-based survey created in QuestionPro that consisted of thirty-four (34) closed-ended questions. In addition to questions concerning student demographics, learning styles, and CIS-related course categories, subsequent questions asked students to identify motivations for either taking or not taking online courses.

The three universities involved in this survey were a private university, a state-owned public university, and a staterelated university. The students surveyed at the private university included those seeking a bachelor's, master's or doctoral degree. The students surveyed at the state-owned and the state-related universities only included those seeking a bachelor's degree. The authors wanted to survey respondents from different types of universities because these universities provide a diverse, socio-economic mixture of participants and potentially different demographics. According to Norvilitis, Merwin, Osberg, Roehling, Young, and Kamas (2006), many demographic differences exist between state and private university students including debt to income ratio and a significant disparity in race. This research strategy of surveying students in different universities is consistent with the survey and data analysis strategy of categorizing research results based on different groups of universities used in the 2017 Noel-Levitz National Student Satisfaction and Priorities Report (2017); however, in the 2017 report, of the online learners surveyed 62\% were undergraduate students and $34 \%$ were graduate students. In this research, more undergraduate students were surveyed than graduate students, by design.

\section{RESULTS}

Only students enrolled in CIS courses completed the survey, regardless of their academic major. Administration of the survey spanned three semesters; spring 2017, fall 2017, and spring 2018. Four hundred and nineteen ( $N=419)$ students answered all questions. The actual number of responses to each question varied by question.

\section{Demographics}

Undergraduate students made up the majority of the survey respondents at $86 \%$. The ratio of male to female students was $70 \%$ male, $29 \%$ female, and $1 \%$ identified as other. Sixty-eight percent $(68 \%)$ of the survey respondents were between 18 and 30 years of age.

\section{Underlying Factors of "Selecting Online" -- Course Effectiveness and Classroom Interaction}

Students were asked: "If given a choice to take the same course in an ONLINE format or an ONGROUND format, would you select the ONLINE format?" With "selecting online" as the dependent variable, a list of independent variables were examined to see which factors affect students" "selecting online." The results in Table 1 show that it is the overall course outcome represented in "the perceived overall effectiveness of courses offered completely online" and the online course structure that encourages "classroom interaction and discussion" that have a highly significant impact on students" "selecting online." The coefficients are positive which suggest that students, who do select online, do so because of perceived overall effectiveness of online courses and classroom interaction and discussion. The pvalues of both contributing factors are less than 0.001 , indicating these factors are highly significant influencers to "selecting online" vs. "selecting on-ground." Moreover, the coefficient for "classroom interaction and discussion" is 0.212 and that for "overall effectiveness" is 0.167 , which shows that "classroom interaction and discussion" carries an even higher weight in students' "selecting online." 
Table 1. Regression Analysis of Underlying Online Selection Factors - All Students

\begin{tabular}{|c|c|c|c|c|c|c|}
\hline & & Coef & cients $^{a}$ & & & \\
\hline & & Unstandardiz & Coefficients & Standardized & & \\
\hline & & B & Std. Error & B & $\mathbf{T}$ & Sig. \\
\hline 1 & (Constant) & .215 & .159 & & 1.348 & .180 \\
\hline & $\begin{array}{l}\text { Perceived OVERALL } \\
\text { effectiveness of courses } \\
\text { offered COMPLETELY } \\
\text { online }\end{array}$ & .167 & .030 & .403 & 5.635 & .000 \\
\hline & Need for Supervision & .100 & .064 & .101 & 1.558 & .121 \\
\hline & Ability to Prioritize & .068 & .068 & .065 & 1.002 & .318 \\
\hline & Effort expected & .043 & .039 & .066 & 1.103 & .272 \\
\hline & $\begin{array}{l}\text { Time-management, I would } \\
\text { describe myself as ... }\end{array}$ & -.005 & .083 & -.004 & -.065 & .948 \\
\hline & $\begin{array}{l}\text { Classroom interaction and } \\
\text { discussion }\end{array}$ & .212 & .047 & .300 & 4.476 & .000 \\
\hline & $\begin{array}{l}\text { I feel that certain subject } \\
\text { areas are more appropriate } \\
\text { to online instruction than } \\
\text { other subject areas }\end{array}$ & .046 & .082 & .032 & .562 & .575 \\
\hline
\end{tabular}

a. Dependent Variable: If given a choice to take the same course in an ONLINE format or an ONGROUND format, would you select the ONLINE format? For all students $\mathrm{N}=419$.

\section{Stated Initial Reasons vs. Underlying Factors}

Table 1 displays the results for all students surveyed along with reasons that they would choose online versus onground courses. As noted, the findings suggest that effectiveness and interaction are the significant factors. In addition to other questions, the survey asked why students initially chose an online course. The exact question asked was: "If you did select an ONLINE format for a course, what would be the main reasons?" The students can choose from Convenience, Scheduling, Delivery Method, To take a particular professor, and Other (please specify).

Based on this perceived reasoning, the authors analyzed the data on what the students chose as their stated reason. First, we parsed the data set and examined students, who stated that they chose online, based on convenience (Table 2). Those, who state that they select for convenience, also decide based on perceived effectiveness and need for classroom interaction, in addition to, expected effort. Time management was not a significant variable, nor was ability to prioritize. Those, who chose for convenience, also require high quality and the need for in-person interaction. In addition, in these analyses we added gender and age, to determine whether these were demographically relevant variables. For students who selected online courses based on convenience, neither age, nor gender was significant. 
Table 2. Regression Analysis of Underlying Online Selection Factor Based on Initial Reason of Convenience

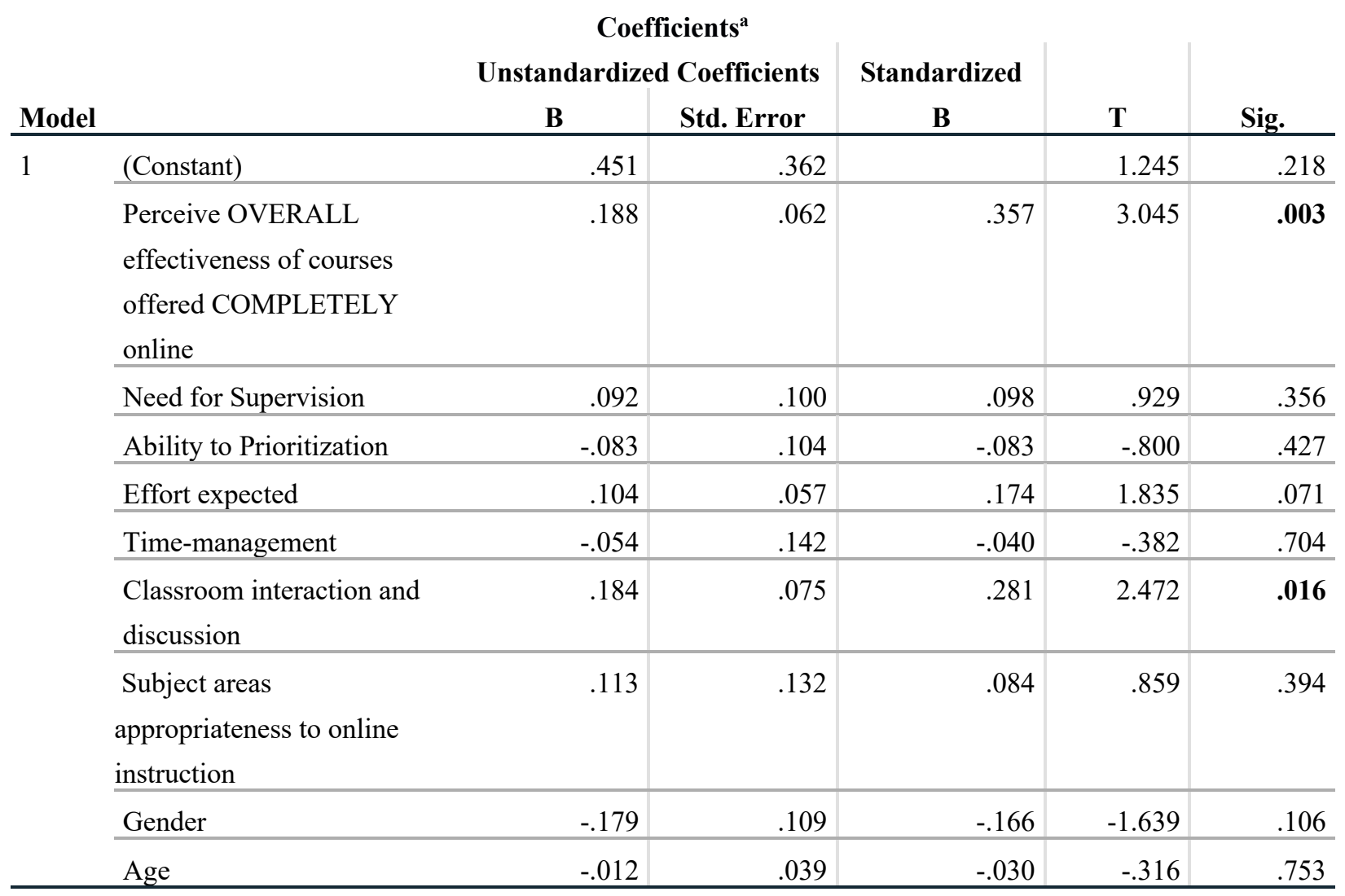

a. Dependent Variable: If given a choice to take the same course in an ONLINE format or an ONGROUND format, would you select the ONLINE format? For those students having chosen Convenience, as the initial reason of having selected online course.

Next, the authors parsed the data set and examined students, who stated that they chose online, based on scheduling (Table 3). Those, who say that they select for scheduling, also decide based on perceived effectiveness, but not the need for classroom interaction, nor expected effort. The ability to prioritize was found to be a significant variable for this group. Online learning does require an internal commitment to study, since there may not be external schedules that are required to be met. It is reasonable that those, who can prioritize, would select online more than those, who cannot. Those, who stated that they chose based on scheduling, also require high quality.

In addition, in these analyses the authors added gender and age to determine whether these were demographically relevant variables. For the student group choosing "scheduling" as the initial reason, gender was not significant, but age was a significant factor for choosing online. A likely assumption is that older students are in the work force and/or have family obligations and need to work schooling around their work and family schedules. Those students, who indicated that they select for scheduling, also decide based on perceived effectiveness, but do not consider classroom interaction. They are significantly older individuals, and they are also students who believe they can prioritize their workload. 
Table 3. Regression Analysis of Underlying Online Selection Factors Based on the Initial Reason of Scheduling

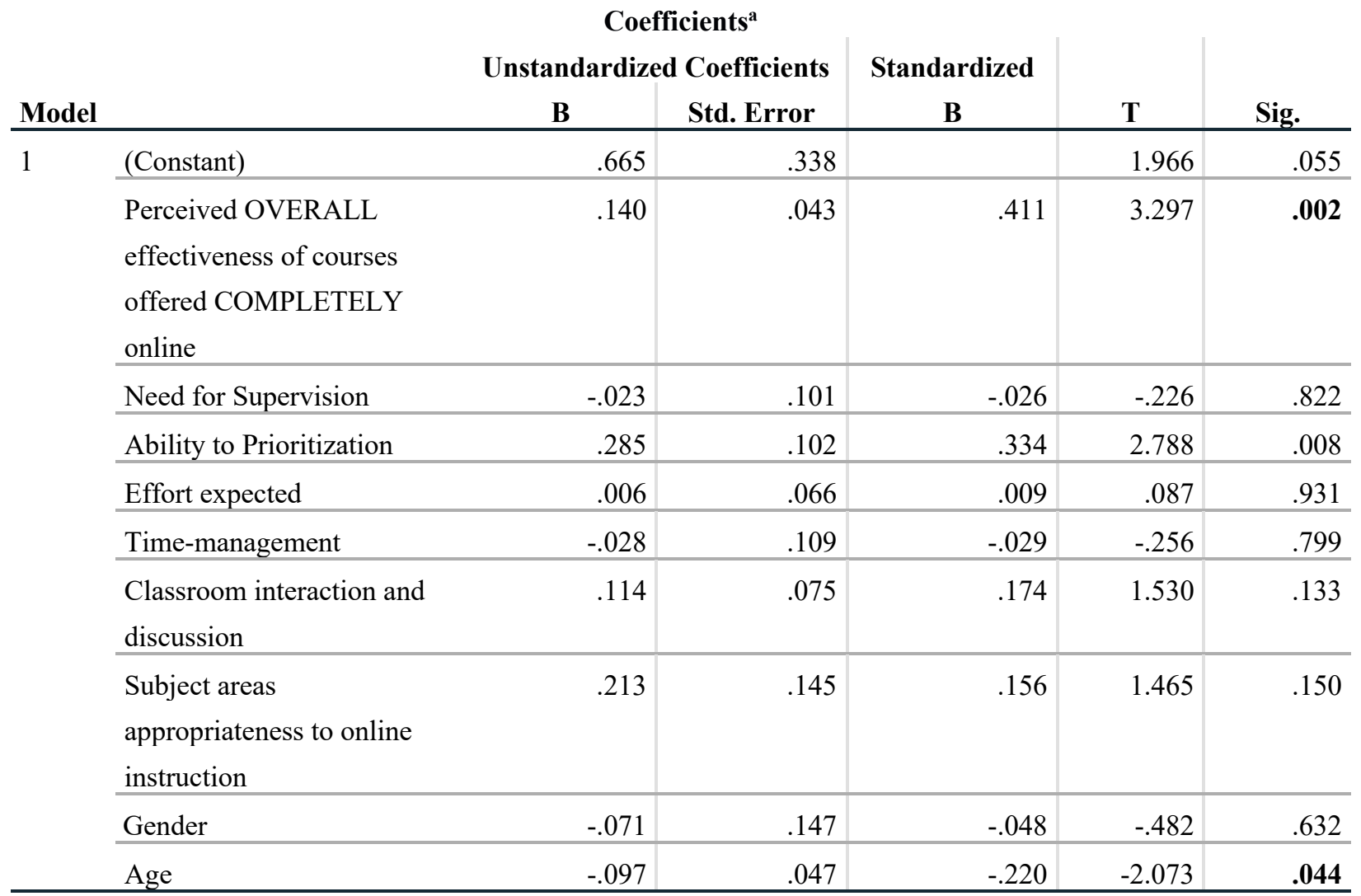

a. Dependent Variable: If given a choice to take the same course in an ONLINE format or an ONGROUND format, would you select the ONLINE format? For those students having chosen Scheduling, as the initial reason of having selected online courses.

The authors parsed the data set again and examined students who stated that they chose online, based on selecting a particular professor (Table 4). The authors found no other significant variables, when a student chooses an online course, based on choosing a particular professor. These students do not seem to care about any other underlying factors. 
Table 4. Regression Analysis of Underlying Online Selection Factors Based on the Initial Reason of Taking a Particular Professor

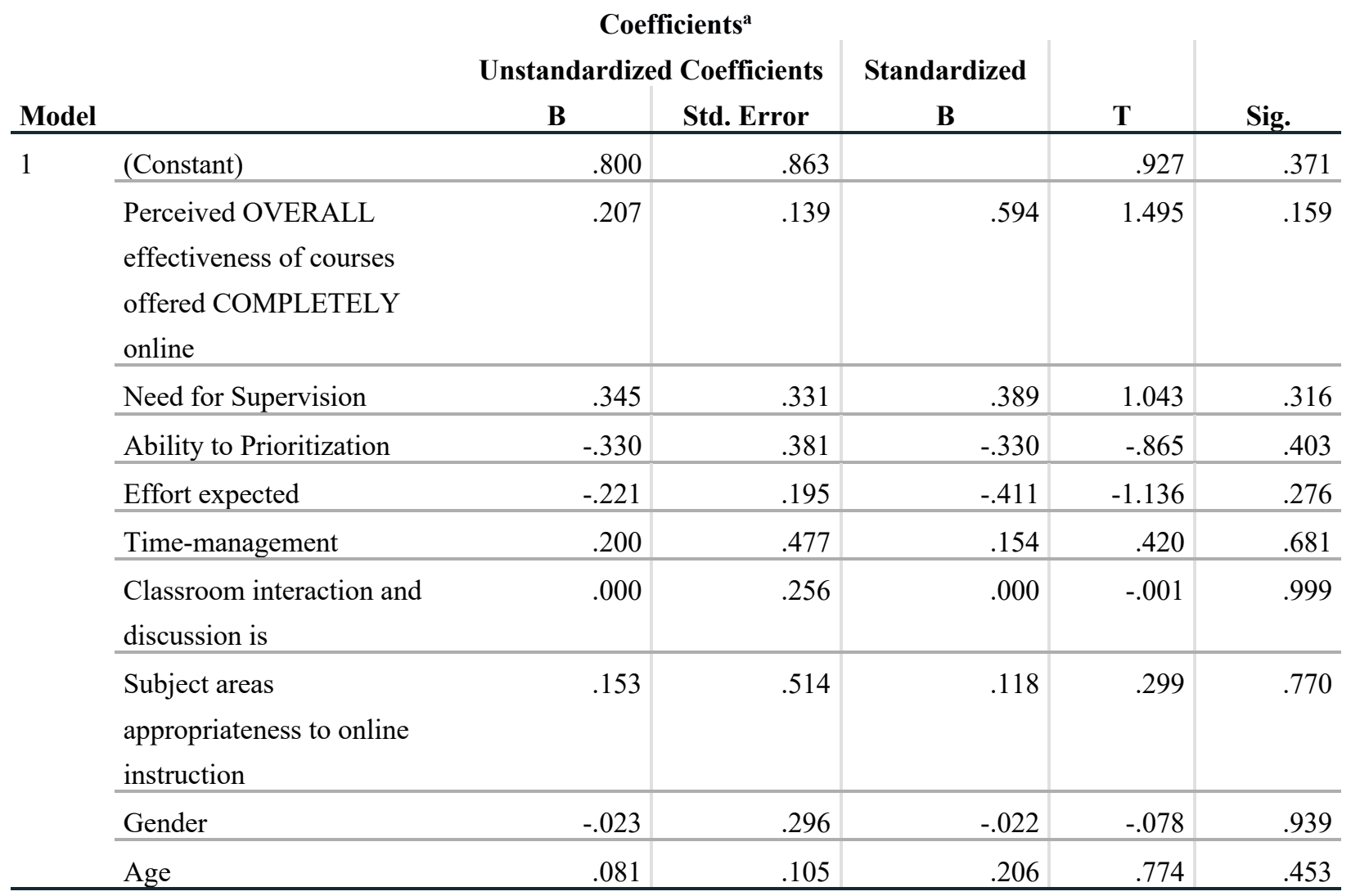

a. Dependent Variable: If given a choice to take the same course in an ONLINE format or an ONGROUND format, would you select the ONLINE format? For those students having chosen based on Taking a Particular Professor, as the initial reason of having selected online courses.

The authors examined the data set a final time and examined students who may have stated that they chose online based on other initial reasons. No students chose an online course, based on other reasons.

Please note that there was not a valid sample size, for those students who chose online due to delivery method, and, therefore, the data could not be analyzed.

\section{DISCUSSIONS}

A key finding of this research for educators suggests that to improve the adoption of online course delivery, as a desired choice, there needs to be a concerted effort to improve perceived and actual online effectiveness, as well as, facilitating online classroom discussion.

The results are interesting as they delve below the existing literature that analyzed convenience, work schedule, and flexible pacing in 2017 (Noel-Levitz, 2017), and convenience, flexible programing, and work schedule in 2012 (NoelLevitz, 2012) and balance other commitment (Hannay and Newvine, 2006). The authors first examined separate independent variables including "time management," "ability to prioritize," "need for supervision," and "effort expected." However, none of these independent variables were a significant influencer to students' "selecting online." In addition, the selection of an online format was not dependent on whether there is a fit between the subject area and 
the online format. This survey differed somewhat in approach, as it asked a question concerning why online versus on-ground was selected, initially. The variables of convenience and flexibility may have influenced an initial choice; however, after making the selection, the underlying factors that correlated with online selection were found to be classroom interaction and overall course effectiveness.

One possible explanation for these significant factors, is that with the pervasiveness and maturity of online education, students are more and more concerned with the quality of online learning rather than the simple convenience and flexibility offered by technology - the factors that have a lesser impact on learning effectiveness and outcome, as they are traits of technology, but not those specifically for education. Students' emphasis on course outcome and course structure, as reasons for selecting online courses, also show the students' maturity in finding the right reasons of choosing the right course delivery format.

The overall effectiveness of courses should always be one of the main reasons for choosing course delivery formats, regardless of online, on-ground or hybrid. The mechanism, (i.e., the "technology") of course delivery does not matter. It is the quality of education, proxied in course effectiveness that really matters.

Online courses typically include forum discussions. Due to the asynchronous nature of online education, especially, that for discussion forums, instructor-to-students and student-to-student interactions and discussions are no longer restricted by the limited class meeting times for on-ground courses. Some discussion forums are designed to encourage more student-to-student interaction (e.g., a student must post at least two threads that address other students' posts). The extent of interactions in an online format would be difficult to match in an on-ground course.

In addition, it is important to note that "the devil is in the details." Online education is evaluated differently by different groups of students. Student groups who have initially elected an online course due to Convenience vs. Scheduling vs. Take a Particular Professor have evaluated differently, the underling factors for their online selection preferences. Online program design tailored to different groups and their preferences would make the program more attractive to these varied groups.

\section{CONCLUSIONS}

This research surveyed over four hundred students in three universities with regard to their preferences of taking online vs. on-ground, or hybrid courses. It found that perceived course effectiveness and classroom interaction were the two major factors that significantly contributed to the selection of an online course delivery format versus an on-ground course delivery format. Students' overall perceived value of online course effectiveness significantly influences their online selection. Classroom interaction and discussion also significantly contributes to online course selection. This research showed that the students, who stated that they selected an online course, initially for convenience, were also influenced significantly, by perceived online course effectiveness and class interaction. Those students, who chose online, initially, based on scheduling, were also influenced by age, perceived effectiveness, and the ability to prioritize. Those, who stated that they chose online, initially for taking a particular professor or for other reasons, were not influenced by any underlying factors.

This study holds significant implications for universities and providers of online education, in that it suggests that there is still a significant need for improving real and perceived effectiveness of online courses and providing significant classroom interaction in online offerings. Acceptance of online education can be improved through addressing these key areas.

\section{REFERENCES}

Allen, I. E., \& Seaman, J. (2015). 2015 Online Report Card - Tracking Online Education in the United States. Babson Survey Research Group and Quahog Research Group. Retrieved from https://onlinelearningconsortium.org/survey_report/2015-online-report-card-tracking-online-educationunited-states/ 
Bristow, D., Shepherd, D. C., Humphreys, M. \& Ziebell, M. (2011). To be or not to be: That isn't the question! An empirical look at online versus traditional brick-and-mortar courses at the university level. Marketing Education Review, 21(3), 241-250.

Driscoll, A., Jicha, K., Hunt, A. N., Tichavsky, L. \& Thompson, G. (2012). Can online courses deliver in-class results? A comparison of student performance and satisfaction in an online versus a face-to-face introductory sociology course. Teaching Sociology, 40(4), 312-331.

Glover, L. C., \& Lewis, V, Evans. (2012) Student Preference Online Versus Traditional Courses. The Global eLearning Journal, v1 n3. Retrieved from https://globalelearningjournal.files.wordpress.com/2012/08/glover-and-lewis-student-preference-onlineversus-traditional-courses-1.pdf

Hannay, M., \& Newvine, T. (2006). Perceptions of Distance-Learning: A Comparison of Online and Traditional Learning. MERLOT Journal of Online Learning and Teaching, 2(1), 1-11. Retrieved from http://jolt.merlot.org/documents/MS05011.pdf

Noel-Levitz, (2012). Noel-Levitz national online learners priorities report. Retrieved from https://www.ruffalonl.com/upload/Papers_and_Research/2012/2012_Online_Leaners_Report.pdf.

Noel-Levitz, (2017). Noel-Levitz national student satisfaction and priority report. Retrieved from https://learn.ruffalonl.com/rs/395-EOG-977/images/2017_National_Student_Satisfaction_Report_1.0.pdf

Ilgaz, H., \& Gülbahar, Y. (2015). A snapshot of online learners: E-readiness, e-satisfaction and expectations. International Review of Research in Open and Distance Learning, 16(2).

Kemp, N., \& Grieve, R. (2014), Face-to-face or face-to-screen? Undergraduates' opinions and test performance in classroom vs. online learning. Frontiers in Psychology. Retrieved from https://doi.org/10.3389/fpsyg.2014.01278

Karambelas, D. (2013). Study: Students prefer real classrooms over virtual. https://www.usatoday.com/story/news/nation/2013/06/11/real-classrooms-better-than-virtual/2412401

Means, B., Toyama, Y., Murphy, R., Bakia, M., \& Jones, K. (2010), Evaluation of Evidence-Based Practices in Online Learning: A Meta-Analysis and Review of Online Learning Studies, ED No. 04-CO-0040, US Department of Education, Office of Planning, Evaluation, and Policy Development, Washington, DC. Retrieved from https://www2.ed.gov/rschstat/eval/tech/evidence-based-practices/finalreport.pdf.

Norvilitis, J. M., Merwin, M. M., Osberg, T. M., Roehling, P. V., Young, P., \& Kamas, M. M. (2006). Personality factors, money attitudes, financial knowledge, and credit-card debt in college students1. Journal of Applied Social Psychology, 36(6), 1395-1413.

Paechter, M., \& Maier, B.(2010) Online or face-to-face? Students' experiences and preferences in e-learning. The Internet and Higher Education, 13(4), 292-297.

Tucker, S. Y. (2012). Promoting socialization in distance education. Turkish Online Journal of Distance Education, 13(1). Retrieved from http://tojde.anadolu.edu.tr/tojde46/articles/article_11.htm

Vidanagama, D. U. (2016). Acceptance of E-learning among undergraduates of computing degrees in Sri Lanka. International Journal of Modern Education and Computer Science, 8(4), 25-32. 